\title{
Analysis of Youth-Oriented Websites
}

\section{An Introduction to the Qualitative Image-Analytical Methods of Objective Hermeneutics}

\author{
Boris ZIZEK \\ Institut of Educational Science, Leibniz Universität Hannover, Germany \\ boris.zizek@iew.uni-hannover.de \\ Hendrik-Zoltán ANDERMANN \\ Institut of Educational Science, Leibniz Universität Hannover, Germany \\ hendrik-zoltan.andermann@iew.uni-hannover.de
}

\begin{abstract}
The following paper is an introduction to the image-analytical methods of objective hermeneutics based on an exemplary analysis of a youth-oriented website. In a methodological sketch, the constitutional and fundamental methodological assumptions, procedures and principles are first explained and substantiated. These will then be carried out using the example of an analysis of the MTV website "A Thin Line" in order to illustrate their practical implementation and to enable self-study.
\end{abstract}

\section{Keywords}

visual data - image analysis - website analysis - qualitative methods - objective hermeneutics - social media

\section{Preliminary Remarks, Questions and Purpose of This Investigation}

The aim of this work ${ }^{1}$ is to present an exemplary analysis of a youth-oriented website as well as to illustrate the example of the reconstructive method of

1 This essay takes data and analysis from a rich website analysis (Zizek 2020). However, this essay has a different focus and aims to serve as a methodological introduction to objective hermeneutics. 
objective hermeneutic analysis of complex visual data in such a way that essential methodological procedures are exemplarily illustrated in their application.

The Internet and social media have developed into an interactive space that has a complex impact on the daily lives of adolescents (Common Sense Media 2015; Leven \& Schneekloth 2015; Turkle 2015), both in the private and public spheres of life (Zeller 2017).The users of this space are confronted above all with a huge and increasing number of visual images, be they pictures, videos or websites (Pennington 2017). Some of the social media platforms have already completely focused on the visual (Laestadius 2017).From a scientific perspective, the question arises what kind of potential and actual influence this has on the development of children and adolescents.

However, text-based research dominated social science for a long time (Bauer 2000) and research tools were lacking to investigate no less significant non-textual communication (Pennington 2017). While many image analytic methods already have difficulties in analyzing simple images, there are few methods for analyzing complex visual data, such as websites, which can contain static elements as well as multilevel moving elements (Quan-Haase \& Sloan 2017). We will discuss this in more detail in the method discussion (see 2.3).

In this paper, we will present the methodological justification of objective hermeneutics (Oevermann 1995 \& 2014) as well as their successive methodological procedures on a concrete analysis in such a way that the contribution fulfills the function of an introduction to the method.

Objective hermeneutics is a reconstructive process that traces the decisions made - be they rational or intuitive - and identifies latent meanings contained therein (Zizek 2012a). As a methodology, objective hermeneutics in a constitutional theory reflects the nature of its object of investigation in order to justify its methodological procedures.

\subsection{The Constitution Theory of Objective Hermeneutics}

For human life practice with its centers of decision (Zizek, 2012b), the coexistence of implicit, intuitive decision modes corresponding to centric positionality and explicit, reflective decision modes corresponding to eccentric positionality (Plessner, 2004) is characteristic. In the form of the decisionmaking mode of centric positionality, Daniel Kahneman also speaks of the instance of fast thinking, which is "the source of your rapid and often precise 
intuitive judgements. And it does most of this without your conscious awareness of its activities" (Kahnemann 2012: ${ }_{5} 8$ ). The eccentric positionality corresponds to the explicit resolution mode of "slow thinking".It is significant that centric positionality (fast thinking) precedes eccentric positionality and maintains a central role in the handling of everyday life situations. The reason for this circumstance lies in the fact that social reality is usually far too complex to be comprehensively reflected in everyday life. In addition, everyday people are usually under time pressure, which means that not all possible actions can be reflected before every decision is made.Adolescents, as well as adults, perform acts that they are not aware of while carrying them out. The precedence of the intuitively operating centric positionality means that we always act and have always been characterized before we extend ourselves in an eccentric position and develop self-images.

Through its sequence-analytic approach, objective hermeneutics examines life-practice decisions by reconstructing them independently of whether they were performed in the mode of fast (centric) or slow thinking (eccentric positionality). As will be shown in more detail below, the respective decision is considered against the background of the also possible action alternatives as a result of a more or less conscious exclusion process. In this way, objective hermeneutics examines human action as dominantly guided by fast thinking.

\subsection{Basic Methodological Assumptions}

In objective hermeneutics it is assumed that the traces and protocols left by the practice of life have an expressive character (Zizek, 2012a; Wernet, 2014). This means that the expressions and actions of the life practice reflect the attitudes of the respective individuals. On the basis of protocols, these statements and attitudes can then be reconstructed in a mode of action-relieved, methodological understanding.

The central objective-hermeneutic procedure of interpreting the meaning of an action is the comparison with options excluded by this action. The meaning of the selected action option is determined by the options that are not selected. For example, the objective meaning of the omission of the greeting response is the "rejection of a common practice."

Another basic, methodical assumption is the rule-guidedness of human action. The subject possesses an intuitive knowledge of universal and culturespecific rules that create the scope for action of the subject. Actions are therefore the result of intuitive or rational selection processes. Some rules are universal (incest prohibition), others are culture-specific (for example, taking off shoes before entering the dwelling or a restaurant). The effectiveness and the status of the rule must be clarified on the respective examination material. Which options open up to the respective case in a concrete action context? 
With the rule concept, the action spaces in which the actor has made his decisions are addressed. If one follows decisions of a case over a certain period of time, one can determine sooner or later a characteristic of a selection from the scopes for actions, which is case-specific and called case structure (Fallstruktur). The notion of structure emphasizes that the choice is characteristic, not random, but based on case-specific dispositions.

\subsection{Some Important Differences to Other Methods of Image Analysis}

In contrast to the "compositional interpretation" (Pennington, 2017: 236, Rose, 2012: 51), for example, objective hermeneutics does not primarily refer to the subjective intention of the image producer, but independently of his actually made decision. In this way one avoids this methodological problem that George Herbert Mead addressed in his rejection of introspection (Mead, 1967:2).

Unlike quantitative content analysis, objective hermeneutics reconstructs image segments in an unbiased way in their concrete structure, while counting of manifest, denotative content (Banks, 2007, Pennington, 2017: 236) invites researchers to subsume under preconceived categories. And there is always a gap between the actual texture of an image segment and the preconceived codes. This is also the case with the categorizing qualitative content analysis (Julien, 2008).

\subsection{The Exploration Power of Sequence Analytical Techniques}

Objective hermeneutics allows methodically to analyze social action independently of the self-interpretation of the actors. Actions can thus be examined in their dynamic process structure and implicit meaning structure.Moreover, the meticulous practice of the procedures described above makes it possible to distance everyday phenomena that are taken for granted, such as the greeting or even the design of a website, and in this way to look at the complex structure of the object of investigation.

It is important for the method of objective hermeneutics that one designs a specific question by which one analyzes the material (see 2.5). In our particular case, the question would be which interactions and latent messages the site generates and shapes through its design.

\subsection{Brief Overview of the Most Important Methodological Steps (Research Guidelines)}

The following methodological steps have been explained above and are carried out in the following example analysis.

1. On the basis of the research question, which you should formulate carefully and in the light of the available research, which data promise new 
insights in this regard. For example, in order to reconstruct different concepts of femininity, one may ask women to take photos of themselves in a chosen environment that they are proud of.

2. Select the cases according to the maxim of maximal contrasting, for example with regard to the milieu of the women, in order to capture the broadest possible spectrum.

3. Initially analyze the individual photos independently of each other and without reference to contextual knowledge, ideally in an interpretation group to counteract one-sided readings. a) Distinguish image segments. b) First analyze the individual segments (e.g. persons, buildings, photo on a website ...) individually, c) then in relation to each other and d) finally in relation to the context (e.g. family photo on a hike, Garz et al., 2014).

4. Formulate comparison categories and possible generalizable hypotheses by contrasting the individual image analyzes and now incorporate at most further research into theoretical modeling.

\section{Basic Information about the Website "A Thin Line" and about MTV}

The website "A Thin Line" was launched in 2010. It addresses adolescents and seeks to facilitate an anonymous interaction between them, with the aim that adolescents can support each other in (social) issues. Among other things, users on this website are able to post short descriptions of social problem experiences in digital media and to obtain an evaluation in the form of a rating or short comments (250 characters). Furthermore, there are some articles on the website about problems that may be associated with the use of digital media, such as sexting.Behind the website "A Thin Line" stands MTV and thus the company Viacom International Media Networks, which is a profit-oriented company that in this case has launched a social initiative. MTV (Music Television) is a music video channel that began broadcasting in 1981 and combined music and television. In the present study, the focus is on the "A Thin Line" website and not on the interaction between the adolescents on this website (Weinstein \& Selman 2014; Weinstein et al., 2015; Zizek, 2017).

\subsection{Preliminary Remarks on the Media Structure of Websites in General}

Unlike images, websites like this one, which will be analyzed in this article, have not only a synchronous but also a diachronic structure. On the one hand 


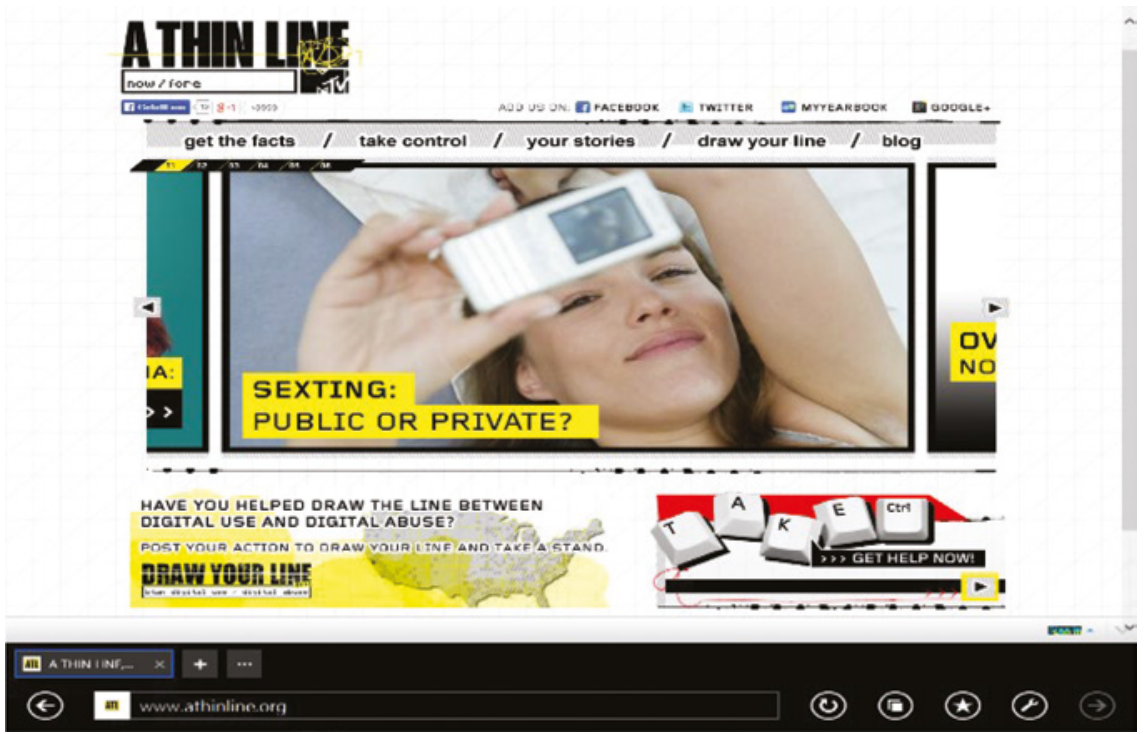

FIGURE 1 Screenshot of the MTV site AThinLine.org (created on July 15, 2016)

image segments are automatically faded in and out one after the other and on the other hand, several layers are found on websites that can be clicked on by the user. Despite the changing picture elements, websites usually do not develop any narration, as is the case with movies. In a first approximation, websites could be characterized as complex images.

Looking at the overall shape of the website, you will notice large font and picture elements, which correspond to the character of a advertising poster. In contrast to illustrated book pages advertising posters aim at a quick perception in passing. The recipient should be addressed as quickly as possible, which should also be done with color eye-catcher elements and certain motifs.

Aside from the previously discussed diachronic structure, websites offer the ability to enter, order or post something on them. With such an ordering function, for example, websites sometimes resemble a complex vending machine, although it must be noted that the delivery is delayed compared to a vending machine. Nevertheless, the immediate, location- and time-independent ordering option is accompanied by enormous time savings as well as a significant increase in selection and comparison options. Also, numerous opportunities for encounters become obsolete by the direct ordering and communication options, so that one is relieved of social encounter.

However, this has the consequence that a training field of social interaction and thus also dealing with personal boundaries is eliminated. 
Websites that allow you to upload or post personal short reports are socially similar to bulletin boards because they are also publicly accessible and can be used to address various issues. On the other hand, bulletin boards are not a place where private information such as personal experience is published. Websites seem to create a new form of bulletin boards in a socially logical way. Also the answer options are massively relieved. While you have to make a note of the bulletin board and then call or write to the person, these efforts on websites do not exist. In this context, one could speak of a low-engagement communication. This meaning can be well illustrated by the example of a handwritten letter or postcard communication, which many still appreciate very much because of the higher cost and the personal touch.

During the analysis, it will become clear that the present screenshot alone with its several picture elements represents a rich analysis material. With this screenshot we have the basic structure of the website in front of us and, secondly, the picture that appears when you first enter the website and thus must be considered as particularly meaningful.

\subsection{Universal Picture Elements and Picture Dimensions}

When dealing with images, single image segments, the relationship of the segments and their common embedding seem to form universal picture elements or dimensions.

Image segments can have both the character of figures, as is the case, for example, with children's drawings in which family members are drawn as animals (Ritter \& Zizek, 2014; Garz et al., 2014; Scheid \& Zizek, 2017) and, as in the present case, image units which each have the character of their own image and show a little pronounced relationship to one another. In order to be able to comprehensively examine the relationship between the image segments, it makes sense to first of all consider them individually.

One reason for recognizing image segments may be because they are outlined, for example, as in the case of the photo in the center of the screenshot. It would also be possible for the image segments to be structured in such a way that the distance to the adjacent image segment forms a boundary or that they have a different coloring or structuring.

For example, the two image segments below the photo additionally create an indirect framing, as their color scheme and their pictorial design are sharply cut off from each other. The map section of the USA in the image segment on the lower left and the aligned buttons in the image segment on the lower right form their own subsegments.

The background can represent a less schematic landscape, which is often the case with children's drawings, or, as in this case, a two-dimensional grid structure that is very abstract and technical in comparison. 
However, before going into the above differentiated image segments and dimensions, it is first necessary to consider the format and its particularities. For example, how do you turn a sheet of paper when you want to draw or paint something, because pictures are usually displayed in landscape or portrait orientation. Only the aspect ratio of screens (16:9 or 21:9) favors the landscape format massively, whereas smartphones prefer the portrait format.

In general, it can be said that pictures in portrait format, such as portraits, tend to emphasize a single picture segment. The landscape format is in turn suitable for displaying a larger space.

\subsection{Conspicuous Features in the Overall Design of the ATL-Website}

4.3.1 Staged Look behind the Scenes - Independent Design

The entire website appears as a picture looking like a composite collage. In the background, a raster pattern is to be recognized, which is reminiscent of a character matrix, which is usually used to allow an exact adjustment of the picture elements. This is similar to a checkered writing pad, which is used for example in a school context. However, the additional diagonal lines are unusual in such a context and intuitively more reminiscent of a professional context, such as a drawing or architectural office.

The colorful picture elements unfold such an effect as if they had been placed on the drawing paper and as if it were possible to move the picture elements. This has the appearance of a draft character, which therefore does not claim to be complete. If one were to find such an image, for example in an artistic room within a school, one would assume that this image has not yet been completed.

An unfinished product, however, provides a first insight into the process of creation. The observer can see that the product was not already finished from the beginning and thus gets a glimpse into the efforts of the creation process. This insight can, for example, lead to a reduction of the asymmetries between viewer and producer and inspire and encourage imitations. In this specific case, however, it can be assumed that the sight of a "not yet finished website" was desired by the operators and designers of the website and thus artificially created. The insight into the creation process is thus staged. On the one hand, the website thus exudes a certain degree of non-bindingness, on the other hand, however, the producers may also intend to express in an aesthetic way their awareness of the future-oriented and provisional nature of creative processes.

Strictly speaking, it could be said that the designers of this website prefer to present themselves as a design avant-garde. Providing users with a website that gives a finished and thoughtful impression does not seem to be the intention of the designers. 


\subsubsection{The Hierarchy of Image Segments as Implicit Sequentiality}

The question now arises how to proceed methodically with the image segments already mentioned. In contrast to an interview, for example, the elements of expression of a picture are not obviously structured by a chronological sequentiality. On the other hand, one must also bear in mind that it is not possible to analyze all image segments simultaneously. Therefore, in such a case it is always advisable to follow the implicit sequentiality of the images. This is present in the hierarchy of the image segments (Oevermann, 2014).

In concrete terms, in the screenshot of the website shown here, a logo, a photo series with a complex framing and two further image units below can be distinguished as image segments. On the one hand, at first glance, the photo on the website stands out because of its central position, size and the intimate motif that it depicts, so one might tend to start by analyzing this image segment. On the other hand, the logo forms a pragmatic framing of the page, as it refers to the producer.

\subsubsection{You Can Choose! - The User as a Consumer}

In the further determination of a possible hierarchy of the image segments, it is noticeable that a high level of autonomy of the image segments is present overall.

Compared to a poster, this website has little hierarchical structure. This is related to the fact that the viewer does not directly understand the relationship between the two lower image segments ("DRAWYOUR LINE" and "TAKE") and the remaining image segments.You could use the logic of the overall structure of this site due to the relatively indifferent range of offerings (such as you would for example, in a vending machine) according to a You can choose! characterize. Thus, the recipient of the website would be addressed as a consumer. By already indicated input possibilities and by the logo, a service is also promised.

\subsubsection{You Have to Decide Quickly!}

A further, very special and outstanding feature of the image, which also deviates from classic advertising spaces, is that the text and image segments change quickly.

With regard to the time interval of the change of the photos on the present website, it can be stated that this is very short and thus no reflective or idle viewing and judgment allows. An example of a rapid change of image or correspondence is represented by digital boards at airports, train stations or in the stock market world.The fast-changing fields, as they are also found in Times 
Square, show the recipient of the preciousness of space and time and at the same time suggest that you are currently on the fast pulse of modern times.

The website presented here also suggests to the viewer that this must be decided quickly, because otherwise the picture changes. This corresponds to the logic of a modern acceleration (Rosa, 2014). However, it cannot be assumed that this rapid change is an intended design of the website, because it would additionally stress the young people and thus undermine the website's intention to help. Here, too, the function was probably chosen because it seemed aesthetically modern to the designers.

\subsection{Analysis of the Individual Image Segments \\ 4.4.1 Analysis of the Logo}

With regard to the logo, it must first be clarified that it basically consists of two levels of expression: verbal and graphic elements. These have to be analyzed separately from each other, as they have inherent, divergent meanings. We can relate these two parts to each other only in a second step, because, more important than the order of analysis of the levels is to make sure that they are analyzed independently.

\subsubsection{The Verbal Level of the Logo}

The term "A thin line" fulfills the characteristics of a headline, as headings usually consist only of a referencing action. The term "thin line" is preceded by the indefinite article "a". Thus, the expression does not refer to a particular thin line.

Unlike a route or a ray, for example, a line is not bounded by two points. In contrast to a route or a stroke, a line is obviously not limited. A line is a stroke that cannot be bypassed. It separates two surfaces from each other.

A thin line is comparatively difficult to recognize. It would be suboptimal to use this as a boundary marker, for example to indicate a ban on overtaking on a carriageway. In such a case, a wide line would be more suitable, which could be designed in such a way that one could even enter it without crossing it. A thin line can also be used to separate two surfaces, but the strong contrast between the separated surfaces is not clearly noticeable. If these assumptions

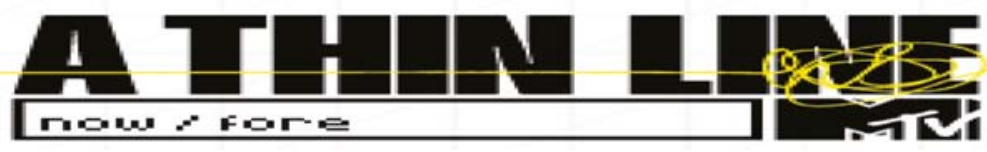

FIGURE 2 Logo of the ATL website (excerpt from Fig. 1) 
are taken further, it can be said that a thin line can lead to (social) problems if the two areas are not sufficiently contrasted. Either you are on one side or the other.

In order to consider the social implications of thin lines, it is necessary to take a closer look at the meaning of such "lines" in social life. It is noticeable that both humans and animals possess their own skin as their own physical border. According to Plessner, life means defending this boundary (Plessner, 2004: 9, Zizek, 2012a).An example would be a scenario where someone lies on a park bench on a cold morning. A passer-by who would want to check whether the person is still alive would first address that person. Only if the passer-by didn't get an answer, one would touch the person and thus what one could call the vital boundary. Beside this bodily, vital boundary there is also a personal boundary of human. This cannot be identified as clearly as the skin at the bodily or vital boundary. The personal boundary is more situation-specific and therefore flexible. It rather addresses the private autonomy space of a person.

\subsubsection{Excursus - Social Thin-Skinnedness}

As can now be seen from the broader inner context, the heading "A Thin Line" does not address the vital boundary, but the personal boundary, and in addition this line is defined as a thin line.

Both in German and in English there is the term "dünnhäutig" or thinskinned. This expression is interesting because it metaphorically transfers the borderline character of the skin to a personal limit. In this context, one could speak of a second type of skin, a social skin. The term "thin-skinned" would thus indicate a lack of flexibility with regard to the personal boundary. Thinskinned people, for example, have a social skin that is not very resilient and therefore quickly claim social consideration. The metaphor makes it clear that the personal boundary is always a product of the social and situation-specific interpretation and that living together of this personal boundary demands a certain flexibility. A certain degree of flexibility is particularly important in diffuse social relationships such as friendships or partnerships.

The title of the MTV initiative as "A Thin Line" points to a current problem situation against the background of these considerations. It is not the social thin-skinnedness that is seen as a problem, but rather the personal border is of course defined by the initiative as a "thin line" and thus regarded as a normality, the maintenance of which everyone should be guided by. The website places itself thus admonishingly in the service of the receipt of this normality assumption: Do not forget, the personal border is thin and easy to transgress!

This would mean that the social skin, i.e. the personal boundary, of the adolescent addressees of this website may be comparatively thin and thus less 
resilient. If this is a generation-specific or cultural tendency, then the question would be where this comes from. This could be due, for example, to the tendency to withdraw from direct interaction as a result of the tendencies of modern growing up and the corresponding way of life, and, as a result, to shun their social impositions and find them particularly unpleasant in the course of this avoidance. You do not stand up for anything anymore, do not expose yourself to any risks or problems, and thus don't learn how to cope, for example, with insults. Sherry Turkle, for example, reports that adolescents she interviewed find it unbearable when, during a meeting between two people, there are moments in which both sides remain silent for lack of discussion (2015). This indicates that a tolerance for failure, for one's own weaknesses and possible embarrassments and the associated willingness to get through or deal with these moments seems to be diminishing.

\subsubsection{The Pictorial Level of the Logo}

In contrast to the naming of an author on a book cover, a logo goes beyond that. It constitutes "...a pictorial illustration of the personal name of an actor offering and/or advertising a particular good or service" (Oevermann 2014: 50). In order for such a function to be fulfilled, however, this illustration must have a thematic reference to the goods/services offered and be as recognizable as possible (Oevermann 2014).

When classifying the picture element "A Thin Line. MTV", one notices the M TV logo at the lower right edge of the picture segment. MTV is an abbreviation, as it is used in other brands (VW, BMW, GM ...). Furthermore, abbreviations of companies or brands are usually designed in a particular way. The logo element "MTV" gets an inner chronology, because the "TV" looks like a graffiti, which has been sprayed on the " $\mathrm{M}$ ". The " $\mathrm{M}$ " is shown larger than the "TV" and thus appears more massive due to its three-dimensional design. The " $\mathrm{M}$ " appears almost as if it were a triumphal arch through whose central space one could pass or an " $\mathrm{M}$ " carved in stone. Thus the " $\mathrm{M}$ " suggests permanence. Like a monument, it refers, as it were, to the function of tradition and timelessness. The "TV", on the other hand, is highlighted, as if it had been sprayed on the large "M". While chiseling, sculpting and building are time-consuming methods, spraying is a fast, less time-consuming process that can be carried out in passing and is less durable.

Due to its volatile character, graffiti is particularly suitable for spontaneous actions. This can also be seen by looking at the "TV" of the logo. In contrast to the " $M$ ", the "TV" is not sprayed horizontally, but diagonally and curved, as if it were a carefree spontaneous expressivity.

If one now compares graffiti and sculpture, graffiti offers a simpler access to the expression of content, but at the same time it also reduces the hurdle for 
such objectification. In contrast to the "TV", the "M" seems cumbersome. However, the fact that the design of such an "M" involves planning and considerations and thus a great deal of effort is ignored.

Also the graffiti "TV" does not have its own design. It does not have its own sprayed background, but was applied on the " $\mathrm{M}$ " and uses the " $\mathrm{M}$ " as background. The graffiti artist doesn't seem to respect the "M",but believes that the "TV" would make the "M" something better. The cumbersome and traditional "M" would be complemented by something relaxed and modern.

Above the company logo is printed in capital letters and printed letters "A Thin Line", which accounts for almost two-thirds of the logo. This makes the "MTV" look like a signature.The lettering "A Thin Line" is also covered by a very thin, yellow line, which acts like a demarcation, which tangles right into a ball of thread. Here the problem of the "thin line" is represented graphically. At first it appears clear, but then it gradually confuses itself into a ball of thread, so that it is no longer possible to determine on which side of the line one is standing. In addition to the already discussed loss of willingness to negotiate and tolerance towards social weaknesses, it is suggested here that a person could easily lose orientation as to which side he/she stands on. It is no longer clear whether you crossed the border or not.

If the wording of the "thin line", as stated above, actually addresses careless dealings with fellow human beings, the design of the logo would show that this line is extremely thin and that particularly sensitive sensory skills are needed to make that line recognize.This design denies both the victims and the perpetrators of social transgressions an important basic social ability in an infantilizing way: The sense of a personal boundary of behavior towards other people.

The website thus presents itself as a product that helps those involved not to unintentionally harm others or to be able to recognize an injury as such from the victim's perspective. Here, a website presents itself as a savior with regard to basic social skills, which at the same time leads to a serious crisis of social boundaries: Young people can apparently no longer be sure what social normality represents. But how can a website help adolescents with this problem? Can it act like a GPS device for social issues and what are the criteria for decision-making?

\subsection{The Centered Photo}

4.5.1 The Inscription on the Photo

The inscription on the photo is "SEXTING: PUBLIC OR PRIVATE?", where sexting means a specific action that is visible on the photo. This is because in 


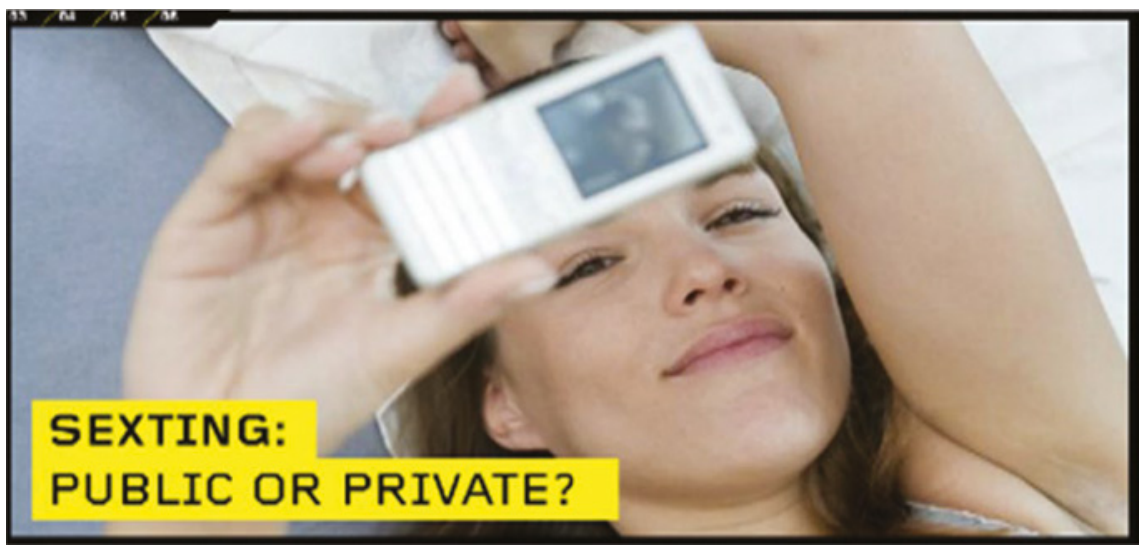

FIGURE 3 The centered photo (excerpt from Fig. 1).

so-called sexting, users use digital media to send each other sexually exciting messages and/or pictures.

In the specific case, the lettering has a neon yellow background. The colored surface is reminiscent of an area colored by a highlighter, as if someone wanted to emphasize the text passage. Here, bright colors like neon yellow or neon green are used to draw attention to these passages.

If the practice depicted in the photo is based on the lettering, the lettering together with the background looks like a kind of judgmental stamping and categorization that has been made, in this case the sexually exciting communication.

It thus seems to be a topic that identifies problems and failures in the intimate sphere of life. The purpose of the topic choice could be to warn the authors of the sexting about these photos and this practice.

If one now includes the sequence "public or private?", then the only question that can be derived from this is whether sexting is carried out publicly or privately or whether, like the photo above, they could not somehow reach the public. If one asks oneself this question and already knows the term sexting, then this reading is obvious. The producers don't ask themselves this question, they address it to the addressees. The mere fact that such a sexting photo can be seen on a website is intended to confront potential addressees with the fact that sexting runs the risk of making such messages or photos "public".

With the marked photo, the producers want to emphasize an action as problematic practice and point it out and admonish the addressee. In this way, the producers are giving themselves a police or pedagogical character and compete in a certain way with existing social institutions. 


\subsubsection{The Centered Photo in Detail}

The pictured photo always appears first when you visit the website. An existing numbering on the top left of the screen also confirms that this is the first photo from a series of photos. As a result, it is given special emphasis for the intention of this website.

The series of pictures is also framed by two thin lines that make the picture (see Figure 3) look like a section from a film or photo roll (see Figure 1). Above the indicated series of pictures there are also short text sequences separated by horizontal lines. These contradict the pictorial metaphor of a movie, since these would have to disappear when a movie is started.

Since the text sequences are positioned above the image series, they also seem to refer to the images. The text sequences are extremely short and they are requests to do something ("get the facts", "take control", "draw your line", "your stories"). It is not a mere product that is being offered, but the website's offer is very likely to refer to an area that can be attributed to therapeutic and educational professions. However, it raises the question of how a website can or should accomplish these tasks ("get the facts" ...).

Centered on the photo is a 17-year-old girl, from whom it is assumed that she still lives with her parents and does not have her own apartment. The picture shows a person who is still in a psychosocial moratorium and therefore not yet grown up. The girl seems to be lying on a bed. In the photo the girl raises her left arm, which is slightly crossed over her head, exposing her armpit as well. In a defensive, antagonistic posture, the girl would stand upright and position the $\operatorname{arm}(\mathrm{s})$ in front of her to use them as a kind of protection or to act offensively with them. But the actual position in the photograph shows that her posture is one that opens up to the maximum, offers her body and displays it to seduce the other. The girl seems to be in a sheltered place, on the bed of a bedroom, for example, which allows an undisturbed physical approach and promises undisturbed intimacy.

The position of the observer is predetermined by the image producer and corresponds to that of the addressee of this erotic offer. It is the perspective of a potential lover.

Although it is highly probable that the photo is a staged photo, it is remarkable that the situation logic reconstructed above was created with it. In order to document the action of sexting, more neutral and distanced perspectives would also have been available, as is the case with some of the other photos on the website. This photo, on the other hand, was chosen as the cover photo and also has an eye-catching effect, similar to the motto "sex sells". However, this goes beyond an objective offer of help. Furthermore, the pictured girl seems to take a selfie in this seductive pose. She has turned the camera side of her mobile 
phone in her direction and you can also see on the display of the mobile phone the outlines of the girl and her attitude. In the practice of erotic selfies arise two main claims: On the one hand, an evaluation is addressed ("Are you still attractive?"), on the other hand, the photo is based on a basis of trust ("You cannot just rely on your partner! He could put the photo on the internet!").

\section{6 “DRAW YOUR LINE” - The Lower Left Image Segment \\ 4.6.1 The Text Sequences}

In this image segment, the request "DRAWYOUR LINE", which was already visible above the photo, is repeated and also written in boldface. Due to the emphasis and the similar design as the logo, this seems to be central for the present picture segment.

The present image (Figure 4) could itself be a promotional poster due to the nature of the design. Below the sequence "DRAW YOUR LINE" is a line, which is designed like an input field, but already has entries. Hereby, the operators might want to indicate that an input function exists on the page. However, it is not possible to enter anything in the input field of this screen segment. It obviously has a purely aesthetic component again.

In this input field "b twn digital use / digital abuse" is written. It is noticeable that " $b$ twn" is probably an abbreviation for "between" and thus an element of youth language. This means that primarily young users are addressed. The entry thus refers to the intermediate area between the use and misuse of digital media.The words in the box thus once again address a borderline issue and that it is important to draw a line between the use and misuse of digital media.

The two lettering "Have you helped draw the line between digital use and digital abuse?" and "Post your action to draw your line and take a stand" clearly

\section{HAVE YOU HELPED DRAW THE LINE BETWEEN DIGITAL USE AND DIGITAL ABUSE?}

PQST YQUR ACTIDN TO DRAW YOUR LINE AND TAKE A STAND.

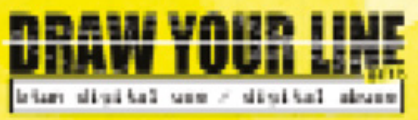

FIGURE 4 Image segment of the ATL website at the lower left edge of the picture (excerpt from Fig. 1) 
refer to the borderline theme of the website. In fact, it is not primarily a question of the individual problem situations of the users, but of their active participation in drawing the line. Here, the user is addressed as a potential part of a seemingly necessary, communal movement and is supposed to connect a general border-drawing action with a personal border-drawing ("Post your action to draw your line...").

\subsubsection{The Picture Elements}

The image segment shows the United States of America (USA). However, the country was cut out of the world map so that the neighboring countries are not visible. This makes it clear that the USA is highlighted here and that it is about them. In an alarming yellow color something seems to approach the USA and to flood, to infect or to take possession of parts of it already in different intensity. For example, both the international sign for disease protection and radioactivity have a neon yellow background.

The yellow "cloud" seems to spread from the south over the USA. The pictorial element thus latently conveys that this danger of "digital abuse" has arisen outside the USA, whereby a complexity-reducing, monocausal attribution of the problem is made. Similar simplistic interpretations can be found again and again for other problems. The current drug problem in the USA for example has not only been caused by the drug cartels in Mexico. As already mentioned above, the website presents itself here as the initiator of a counter-movement, thus raising the significance of the project visually to the level of a national defensive action, with which it also ascribes itself an enormous impact.

\section{$4 \cdot 7$}

\section{"TAKE" - The Lower, Right Image Segment}

The first thing you notice when looking at this image segment is that the image and text elements are very strongly interwoven (letters and keys). The most conspicuous element is the loose and randomly falling computer keys, which are positioned against a red background.This red background looks like an energetic train going into the picture, moving on a black line reminiscent of rails. The passing train seems to be the reason that the keys are tangle and loose. In addition to the train, which moves from the left into the image and moves to the right, there are other, direction-indicating elements: On the one hand there is the start button in the lower right part of the picture, the red arrows positioned to the left and the three arrows next to the text segment "GET HELP NOW!" They all point in the same direction.

In the image segment is thus on the one hand a highly modern, fast means of transport (the train) to be seen and on the other side large, antiquated keys, which are whirled up by the train. Because of this contrast, one might be 


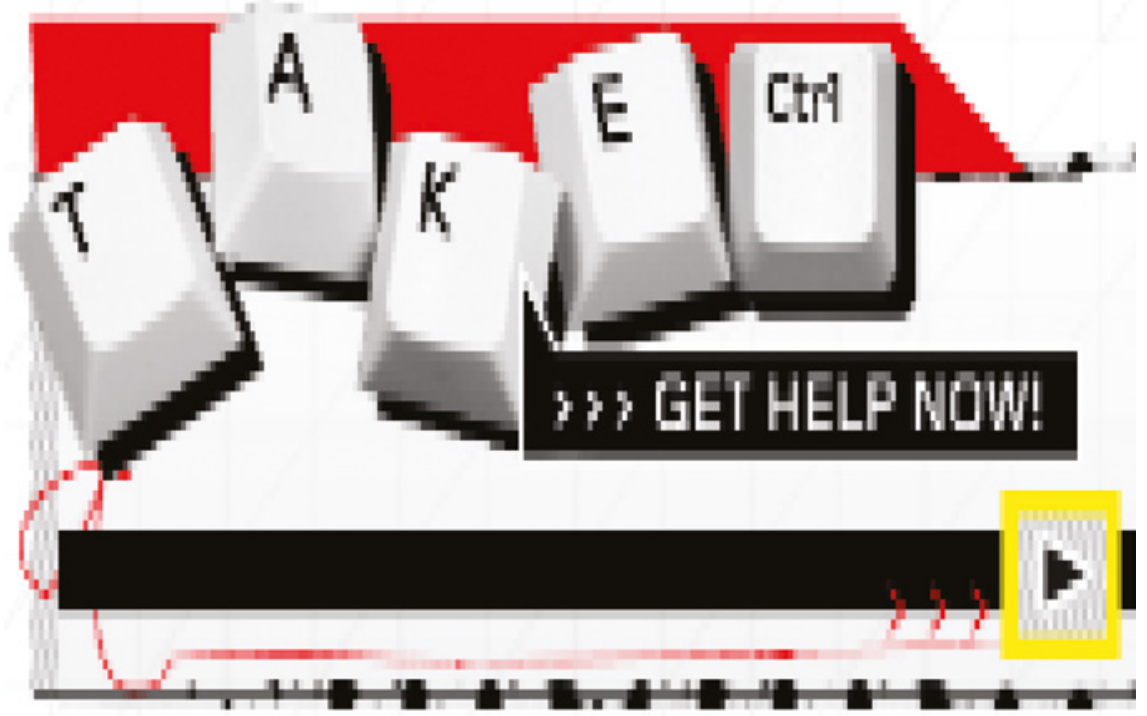

FIGURE 5 Image segment of the ATL website at the bottom right of the screen (excerpt from Fig. 1)

inclined to say: Who has such an old, clunky-looking keyboard? Touchscreen buttons or thin laptop keys would be modern. The remaining elements of the picture are also displayed in a more delicate way than the buttons shown here, for example the fine strokes of the arrows or the thin, red lines.

The thin, red lines are reminiscent of the structure of a kind of string and thus indirectly refer to the name of the website ("A Thin Line").

The image segment thus plays latently and with a certain light, ironic condescension with the motif of being overwhelmed by complex technology. The less technophile user knows that he is at the right address here. Perhaps by clicking on the start button with a yellow border he will get the corresponding help.

It is also noticeable that the keys do not fall completely out of place, but are arranged in such a way that the statement "take ctrl" (take control) results and thus refers to one of the lettering in the middle image segment of the entire website.

Taken in isolation, this image segment refers to some extent to the other image segments of the website, but not to the overall intention of the website. At best, the "get help now" resembles the prompts in the middle image segment. However, it does not repeat the request of the "Draw Your Line". 


\section{Conclusion}

\subsection{Preliminary Remarks}

As already mentioned, the website has been designed to enable young users to exchange information on social problems, especially regarding social border crossings. The rationale behind the "A Thin Line" initiative was certainly that young people are more likely to turn to peers for help with problems.

The chosen research method refers, and this represents the central potential of objective hermeneutics, to the level of latent sense structures. We have before us various decisions on action and design that have arisen in the everyday mode of short-term decision and understanding without complete rational interpenetration. Therefore, habitual and contemporary influences have an effect, which the creators have made on the already thematized level of fast thinking, i.e. intuitive decisions.

The investigation shows that websites are an excellent projection field for aesthetic design, influenced by the zeitgeist, cultural currents and tendencies, in particular because of their complex structure working with pictorial elements in a variety of ways. However, the cultural trends and attitudes revealed by the analysis do not seem to be typical only of the "A Thin Line" website.

\subsection{The Website as a Socializational Context}

The intended focus of the website is to provide exchange and information about violations of the personal border. Due to the way the individual image segments and text elements are designed, the website transports interpretations and solution strategies of this problem, which will be summarized in the following.

The logo of the website contains the tangle formation of a line, which thematizes a loss of orientation on the part of the adolescents, as a result of which they have lost consciousness for social boundary crossings. They no longer even know which side of the line they are on and thus appear to be as helpless as possible. In the map image segment, this problem is even interpreted as coming from the outside, which reduces the complexity of the problem by suppressing possible adolescent contributions. They could gain the view from this perspective that they themselves have nothing to do with the problem.

To this implicit interpretation of the problem it fits that the users are addressed here as customers. As a customer, you are not involved in problem solving, but expect a finished product. Transferred to other contexts in the fields of education and therapy, however, this attitude should be considered 
inappropriate and harmful, according to the saying: Let me have my cake and eat it too. Because in a therapy, the patient is always part of the solution.

In contrast to the thesis on social thin-skinnedness already developed above, the problem is not seen by the website operators as an erosion of the ability to deal with (i.e. the so-called social skills), but is reduced to a mere problem of definition and location: If one knew where the border was and pointed to it, then the problem would be solved. The type of problem solving thus corresponds to a technical view of social problems and that these could be solved by algorithms. In a deautonomizing way, problem-solving strategies are handed over to technical support. In this way, social apps would eradicate important development incentives and social thin-skinnedness would no longer seem to be a problem.

From an aesthetic point of view, the website presents itself as technically potent and creative. The website was designed to be presented as a work-inprogress, but with the appearance of being non-binding. It seems to be in line with a postmodern, aesthetic attitude, to appear consciously without obligation and not to commit oneself. This, however, conflicts with the social intended function of the website.

A similar attitude can be found in the design of the logo, which on the one hand represents a spontaneous expressivity and on the other hand interprets elaborate planning as unnecessary sluggishness. A central, modern discourse becomes clear in the logo, namely the relationship to tradition and the understanding of the constructive and creative. In the other picture elements, too, this is accentuated by the old-looking keys on the one hand and the futuristic express train on the other.

On the positive side, it could be said that the light-hearted way of designing encourages the appropriation of traditional collections and removes obstacles to self-expression. Users are also encouraged to involve themselves in the process of demarcating boundaries.

On the negative side, it can be said that a too careless dismantling of traditional holdings also encompasses cultural manners and can therefore also contribute to the illustrated tangling of personal boundaries.

Another structural problem of the website could be identified. MTV presents itself through this website as a charitable initiator of a movement that wants to set a tone in terms of digital use and digital abuse. By fading in the logo (MTV), however, this is a clever promotion. This contradicts not only the propagated social intention of the company, which in this way also competes with social institutions. In this way, it also desensitizes users with regard to important social demarcations, that is, between public interest-oriented and societal-business relationships. 
The analysis has shown how complex the meaning structure of an image is and how much more complex that of a website is, which requires a successive analysis of fixed and moving image and font elements, which can also be arranged on several levels. A sequential analysis, as provided by objective hermeneutics, is able to capture this complexity and to work out the inner structure of seemingly disparate pictorial designs. Thus, it gradually emerged that the design of the individual image segments, which at first appear completely disjointed, follows common structural principles.

It has also become clear that the latent meaning of pictorial designs can deviate greatly from the conscious intention. We have formed the most farreaching structural hypotheses on the level of the latent sense structure. According to them, the latent meaning of the individual website elements directly contradicts the intention of the website. It is also important to reconstruct the latent meaning structures of social phenomena such as websites because they have a considerable, if not decisive, socializational effect. They structure the social space of experience, permit some actions or perceptions and exclude others.

The sequential, meticulous interpretation of the individual image segments, which demands the procedures of objective hermeneutics, thus also turns apparently self-evident phenomena of everyday life, such as a website, into research objects in need of explanation, and thus, as we have seen, is able to distance them. In this way it also enables, as has become clear above, a substantial, critical examination of phenomena of the everyday world.

\section{References}

Banks, M. (2007).Using Visual Data in Qualitative Research. SAGE.

Bauer, M.W. (2000). Analyzing noise and music as social data. In M.W. Bauer \& G. Gaskell (Eds.) Qualitative Researching with Text, Image and Sound (pp. 263-281). SAGE.

Common Sense Media (2015). The common census. Media use by tweens and teens. http://www.commonsensemedia.org/census.

Garz, D., Zizek, B., \& Zizek, L. (2014). Familienpositionalitäten. Zur Rekonstruktion familialer Lebenswelten, In K. Kraimer (Ed.), Aus Bildern lernen. Optionen einer sozialwissenschaftlichen Bild-Hermeneutik (pp. 76-107). Münstermann.

Julien, H. (2008). Content analysis. In L. Given (Eds.), The SAGE Encyclopedia of Qualitative Research Methods (pp. 120-121). SAGE.

Kahneman, D. (2012). Schnelles Denken, langsames Denken. Siedler. 
Laestadius, L. (2017). Instagram. In L. Sloan \& A. Quan-Haase (Eds.), The Sage Handbook of Social Media Research Methods (pp. 573-592). SAG E.

Leven, I. \& Schneekloth, U. (2015). Freizeit und Internet: Zwischen klassischem "Offline und neuem Sozialraum. In Shell Deutschland Holding (Ed.), Jugend 2015 (pp. 111153). Fischer.

Mead, G. H. (1967). Mind, Self, \& Society. From the Standpoint of a Social Behaviorist. University of Chicago Press.

Oevermann, U. (1995). Die objektive Hermeneutik als unverzichtbare methodologische Grundlage für die Analyse von Subjektivität. Zugleich eine Kritik der Tiefenhermeneutik. In Jung et al. (Eds.), “Wirklichkeit” im Deutungsprozess: Verstehen und Methoden in den Kultur- und Sozialwissenschaften (pp. 106-189). Suhrkamp.

Oevermann, U. (1996). Theoretische Skizze einer revidierten Theorie professionalisierten Handelns. In A. Combe \& W. Helsper (Eds.), Pädagogische Professionalität. Untersuchungen zum Typus pädagogischen Handelns (pp. 70-182). Suhrkamp.

Oevermann, U. (2014). "Getting Closer" - Bildanalyse mit den Verfahren der objektiven Hermeneutik am Beispiel einer Google Earth-Werbung. In K. Kraimer (Ed.), Aus Bildern lernen. Optionen einer sozialwissenschaftlichen Bild-Hermeneutik (pp. 129-177). Münstermann.

Pennington, D. R. (2017). Coding of Non-Text Data. In L. Sloan \& A. Quan-Haase (Eds.), The Sage Handbook of Social Media Research Methods (pp. 232-250). SAGE.

Plessner, H. (2004). Der Mensch als Lebewesen. In H. Plessner (Ed.), Mit anderen Augen. Aspekte einer philosophischen Anthropologie (pp. 224-262). Reclam.

Quan-Haase, A. \& Sloan, L. (2017). Introduction to the Handbook of Social Media Research Methods: Goals, Challenges and Innovations. In L. Sloan \& A. Quan-Haase (Eds.), The Sage Handbook of Social Media Research Methods (pp. 1-10). SAGE.

Ritter, B., \& Zizek, B. (2014). Aufschlusspotentiale - Zur schöpferisch-ausdruckshaften Aneignung der Primärgruppe und der eigenen Positionalität in Kinderzeichnungen. In K. Kraimer (Ed.), Aus Bildern lernen. Optionen einer sozialwissenschaftlichen Bild-Hermeneutik (pp. 107-165). Münstermann.

Rosa, H. (2014). Beschleunigung und Entfremdung. Entwurf einer kritischen Theorie spätmoderner Zeitlichkeit. Suhrkamp.

Rose, G. (2012). Visual Methodologies: An Introduction to Researching with Visual Methods. SAGE.

Scheid, C. \& Zizek B. (2017). Methodische und konstitutionstheoretische Aspekte einer rekonstruktiven Kindheitsforschung. Analysen von Kinderzeichnungen als Zugang zu kindlichen Bildungsprozessen. Sozialer Sinn, 18 (1), 1-6. https://doi.org/10.1515/ sosi-2017-0001.

Turkle, S. (2015). Reclaiming conversation. The power of talk in a digital age. Penguin.

Weinstein, E.C. \& Selman, R.L. (2014). Digital stress: adolescents' personal accounts, New Media \& Society, 1-19. https://doi.org/10.1177/1461444814543989. 
Weinstein, E.C., Selman, R.L., Thomas, S., Kim, J.E., White, A.E., Dinakar, K. (2015). How to cope with digital stress: the recommendations adolescents offer their peers online. Journal of Adolescent Research, 1-27. https://doi.org/10.1177/0743558415587326.

Wernet, A. (2014). Hermeneutics and objective hermeneutics. In U. Flick (Ed.) The SAGE Handbook of Qualitative Data Analysis (pp. 234-246). SAG E.

Zeller, F. (2017). Analyzing social media data and other data sources: a methodological overview. In L. Sloan \& A. Quan-Haase (Eds.), The Sage Handbook of Social Media Research Methods (pp. 386-404). SAGE.

Zizek, B. (2012a). Vollzug und Begründung, objektive und subjektive Daten. Eine Parallele?. Sozialersinn, 1/2012.

Zizek, B. (2012b). Probleme und Formationen des modernen Subjekts. Zu einer Theorie universaler Bezogenheiten. Springer VS.

Zizek, B. (2017). Digital socialization? an exploratory sequential analysis of anonymous adolescent internet-social interaction, Human Development, 6o, 203-232.

Zizek, B. (2020). Digital Youth - Exemplarische objektiv-hermeneutische Analyse der MTV-Website A Thin Line. In C. Detka (Ed.), Erkenntnispotentiale rekonstruktiver Sozialforschung: Ulrich Oevermann und Fritz Schütze. Objektive Hermeneutik und soziolinguistische Prozessanalyse. Ein Methodenvergleich. Budrich.

\section{Other References}

Fig. 1: Self-made Screenshot of the MTV site AThinLine.org (created on July 15, 2016). Figs. 2-5: Excerpts of the screenshot of Fig. 1. 